Research Article

\title{
Effective Semiactive Base Isolation System under Multiple Earthquakes
}

\author{
Mohtasham Mohebbi (D) and Hamed Dadkhah \\ Faculty of Engineering, Department of Civil Engineering, University of Mohaghegh Ardabili, Ardabil, Iran \\ Correspondence should be addressed to Mohtasham Mohebbi; mohebbi@uma.ac.ir
}

Received 22 August 2017; Revised 11 December 2017; Accepted 13 December 2017; Published 27 February 2018

Academic Editor: Hossein Moayedi

Copyright (C) 2018 Mohtasham Mohebbi and Hamed Dadkhah. This is an open access article distributed under the Creative Commons Attribution License, which permits unrestricted use, distribution, and reproduction in any medium, provided the original work is properly cited.

A method is proposed to design an effective semiactive control system composed of a linear low damping base isolation and a supplemental magnetorheological (MR) damper when the structure subjected to multiple earthquakes. In the proposed design method, the parameters of semiactive control system have been determined based on minimizing the average of maximum response of isolated structure under multiple design ground motions. To select appropriate value for force related weighting parameter, defined in performance index, a range has been suggested for each design objective. For numerical simulations, a scaled three-story base-isolated frame subjected to different scaled real earthquakes as well as filtered white noise excitations and the proposed method has been applied to design semiactive base isolation system under multiple earthquakes. The results of numerical simulations have shown the capability of the proposed method in designing an effective semiactive base isolation system, the performance of which under multiple earthquakes has been almost close to the case that it is designed optimally for each earthquake separately. Also, under multiple earthquakes, using the passive-off and passive-on forms of MR damper can be recommended, respectively, regarding to the objectives of minimizing the maximum acceleration and base drift.

\section{Introduction}

Base isolation system is widely recognized as one of the most effective control strategies used for mitigating the structural response, which helps a structure survive a potentially devastating seismic impact through a proper initial design or subsequent modifications. In many cases, the application of the base isolation system has been considerably helpful in improving a structure's seismic performance and its sustainability. However, being a passive control system, it suffers from some limitations such as large base drifts and the inability to adapt to different earthquakes and vibrations. To reduce the base drift of base isolation system, different strategies have been previously considered including increasing the damping of the natural rubber [1] and using supplemental passive dampers in conjunction with the base isolation system [2]. More recently, in order to both mitigate the base drift and make the base isolation system adaptable to different earthquakes, using active and semiactive control schemes along with the base isolation system have been investigated. The active control systems directly apply the desired force for controlling the seismic response of structures, [3] while in the semiactive control schemes, the characteristics of control system are adjusted to make the applied force track the desired control force. Hybrid active base isolation systems have been studied by a number of researchers [4-6] and have shown effective performance in both mitigating the base drift and adapting to different conditions. Nagarajaiah et al. [5] performed an experimental and analytical study to investigate the effectiveness of an active base isolation system in controlling a slidingisolated bridge and found significant reduction in the response of the bridge. Since active control systems 
require high external power supplies, semiactive systems have been proposed to replace them. Several semiactive mechanisms have been examined in combination with the base isolation system such as variable orifice damper $[7,8]$ and variable stiffness system $[9,10]$. Weber et al. [11] studied the performance of structure equipped with a semiactive friction pendulum against the seismic loading and determined the optimal friction coefficient of isolation system for minimizing the structure acceleration. Magnetorheological (MR) damper is also another effective semiactive control system considered separately $[12,13]$ or together with the base isolation system for controlling the structural response [14-18]. Ramallo et al. [19] demonstrated the effectiveness of adding a MR damper to conventional isolated structures by achieving notable decreases in base drifts compared to passive systems. Sahasrabudhe and Nagarajaiah [20] proved experimentally the effectiveness of the semiactive base isolation system in reducing the base drift and other response of the superstructure under near-field earthquakes.

In previous researches, mostly only one excitation has been used in the design procedure of semiactive control system while the characteristics of earthquakes may strongly affect its performance. As examples, for designing a semiactive base isolation system, Johnson et al. [21] designed the control system under one excitation, and Yoshioka et al. [22] used the $\mathrm{H}_{2} / \mathrm{LQG}$ algorithm to minimize the peak acceleration under only the El Centro earthquake. Also, Mohebbi et al. [23] determined the optimal weighting parameter of semiactive base isolation system under one excitation with design objective of minimizing the peak base drift. However, although Ramallo et al. [19] designed the control system to reduce the base drift without increasing acceleration based on the results of four historical earthquakes, they determined the design variables of the control algorithm based on try and error.

Hence, in previous researches which use only one excitation in designing semiactive base isolation systems, the effect of earthquake characteristics on designing and performance of semiactive base isolation has not been studied in detail. On the other hand, according to regulations of seismic design codes, to take into account the effect of different earthquake characteristics in design output and design a structure to be resistant under different excitations, it is recommended to consider multiple design records in a design procedure where the design records are selected based on site seismic condition. Therefore, following this recommendation and extending it in designing control system to be effective under different earthquakes, in this paper, it has been decided to design the semiactive base isolation system based on considering multiple earthquakes in the design procedure that the earthquake records have been selected randomly. However, in addition to considering the randomly selected earthquake records, the filtered white noise excitations are considered in this paper. If the obtained results based on the selected earthquakes are satisfied under the filtered white noise excitations, it can be concluded that the results are valid for a wide range of earthquakes as well as sits. Also instead of trial-and-error method, a systematic procedure is explained to design the semiactive base isolation system. According to the seismic design codes, the acceleration and drift have been known as the proper criteria of designing structure that, respectively, represent the criteria of the occupant comfort ability and the structure safety. In most previous researches, it has been seen that the maximum acceleration of isolated structure increases when adding the supplemental MR damper to the base isolation system which can cause problems regarding occupant comfort ability criterion $[23,24]$. Hence, in this research, controlling the base drift and superstructure acceleration separately or simultaneously under multiple records has been considered as design objectives. For numerical simulations, a threestory frame subjected to different earthquakes and for different design objectives, the parameters of control system have been determined based on minimizing the average of responses obtained under several excitations. In addition, the performance of control system designed based on using multiple records in the design procedure has been evaluated under different test records.

\section{System Model}

Assuming that the performance of the hybrid base isolation and MR damper system is adequate to keep the structure in the linear region, the equation of motion of the semiactive base isolation system can be written as

$$
M_{s} \ddot{x}+C_{s} \dot{x}+K_{s} x=\Gamma f-M_{s} \Lambda \ddot{x}_{g},
$$

where $\Gamma=\left[\begin{array}{ll}-1 & 0_{i \times 1}\end{array}\right]^{T}$ which indicates the position of MR dampers, $\Lambda$ is the vector that all of its components are unity, $f$ is the force of the MR damper, $\ddot{x}_{g}$ is the ground acceleration, $x$ is the vector of the displacements of the structure relative to the ground, and $M_{s}, K_{s}$, and $C_{s}$ are the mass, stiffness, and damping matrices of controlled structure, respectively.

The state-space form of the equation of motion is given by

$$
\begin{aligned}
& \dot{Z}=A Z+B f+E \ddot{x}_{g}, \\
& y=C Z+D f+\nu,
\end{aligned}
$$

where $Z$ is the state vector $\left(Z=[x, \dot{x}]^{T}\right), v$ is the measurement noise vector, $y$ is the vector of measured outputs, and $A, B, C, D$, and $E$ are the system matrices. Defining $y$ as the vector that includes the acceleration of the base isolation, floor accelerations of the isolated structure, and the displacement of the base isolation (i.e., $y=\left[\ddot{x}_{1}, \ldots, \ddot{x}_{n}, x_{1}\right]$ ), the system matrices of (2) and (3) for a system with $n$ degrees of freedom can be written as 


$$
\begin{aligned}
& A=\left[\begin{array}{cc}
0_{n \times n} & I_{n \times n} \\
-M_{s}^{-1} K_{s} & -M_{s}^{-1} C_{s}
\end{array}\right], \\
& B=\left[\begin{array}{c}
0_{n \times 1} \\
M_{s}^{-1} \Gamma
\end{array}\right] \text {, } \\
& E=\left[\begin{array}{c}
0_{n \times 1} \\
\Lambda_{n \times 1}
\end{array}\right] \text {, } \\
& C=\left[\begin{array}{cc}
-M_{s}^{-1} K_{s} & -M_{s}^{-1} C_{s} \\
1,0_{1 \times n-1} & 0_{1 \times n}
\end{array}\right] \text {, } \\
& D=\left[\begin{array}{c}
M_{s}^{-1} \Gamma \\
0
\end{array}\right] \text {, }
\end{aligned}
$$

\section{MR Damper Model}

MR dampers are semiactive control systems whose dynamic behaviors can easily be adjusted by changing voltage levels. This enables the device to produce high variable damping forces with less energy requirements than other devices of its class. So hybrid isolation systems consisting of the base isolation system and MR dampers can reasonably adapt to different excitations even to near-field earthquakes where the isolated structure is more susceptible to damage [25]. A simple mechanical idealization of the MR damper is depicted in Figure 1. [26]

The applied force, $f$, predicted by this model is given as

$$
f=a z+c_{0}(\dot{x}-\dot{y})+k_{0}(x-y)+k_{1}\left(x-x_{0}\right)
$$

or equivalently

$$
\begin{aligned}
& f=c_{1} \dot{y}+k_{1}\left(x-x_{0}\right), \\
& \dot{z}=-\gamma|\dot{x}-\dot{y}| z|z|^{n-1}-\beta(\dot{x}-\dot{y})|z|^{n}+A(\dot{x}-\dot{y}), \\
& \dot{y}=\frac{1}{c_{1}+c_{0}}\left\{a z+c_{0} \dot{x}+k_{0}(x-y)\right\},
\end{aligned}
$$

where $k_{1}, c_{0}$, and $c_{1}$ represent the accumulator stiffness, the viscous damping, and the dashpot, respectively. $x_{0}$ is the initial displacement of spring $k_{1}, k_{0}$ is present to control the stiffness at the large velocities, and the parameters $\gamma, \beta$, and $A$ are the parameters used to define the shape of hysteresis loops.

The force of the MR damper depends on its voltage. Spencer et al. [27] have suggested the following equations to obtain the dynamic parameters of the MR damper:

$$
\begin{aligned}
a & =a(u)=a_{a}+a_{b} u, \\
c_{1} & =c_{1}(u)=c_{1 a}+c_{1 b} u, \\
c_{0} & =c_{0}(u)=c_{0 a}+c_{0 b} u,
\end{aligned}
$$

where $u$ is given as the output of a first-order filter given by

$$
\dot{u}=-\eta(u-V),
$$

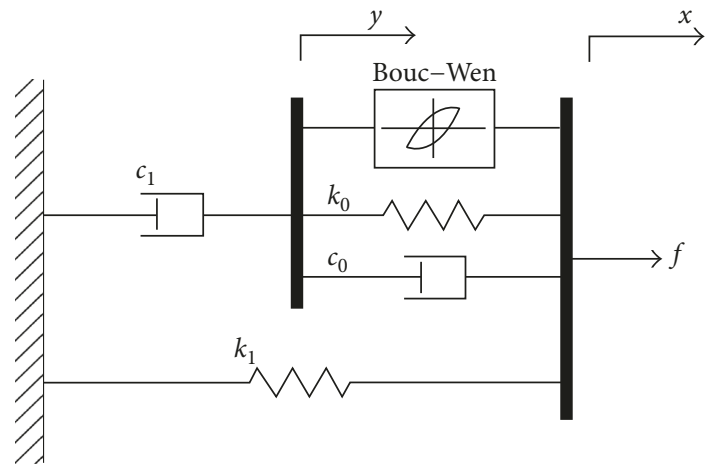

FIgURE 1: Simple mechanical model of MR damper.

where $V$ is the MR damper voltage and $\eta$ is a constant modulus with dimension of $\sec ^{-1}$.

\section{Control Algorithm}

In this paper, the $\mathrm{H}_{2} / \mathrm{LQG}$ control algorithm has been used to determine the optimum control force required for mitigating the response [28]. To design the controller, $\ddot{x}_{q}$ is taken to be the stationary white noise, and the response of the structure is minimized using the following cost function:

$$
J=\lim _{\tau \rightarrow \infty} \frac{1}{\tau} E\left[\int_{0}^{\tau}\left(y^{T}(t) Q y(t)+r f_{c}^{2}\right) d t\right],
$$

where $Q$ and $r$ are the response weighting matrix and force weighting parameter that affect the performance of the active and semiactive control systems [29] and should be selected properly. Similar to the previous researches in designing semiactive control systems, in this paper, too, the response related weighting matrix $Q$ has been considered such that different weights are assigned to accelerations and drifts as follows [19, 21]:

$$
Q=\left[\begin{array}{cc}
q_{\text {accels }} I & 0 \\
0 & q_{\text {drifts }} I
\end{array}\right],
$$

where $q_{\text {accels }}$ and $q_{\text {drifts }}$ are, respectively, the weights assigned to the accelerations and drifts of the structure. In this paper, the output vector, $y$, includes accelerations of the stories and the base drifts, $y=\left[\ddot{x}_{b}, \ddot{x}_{1}, \ldots, \ddot{x}_{n}, x_{b}\right]$; hence, the cost function defined in (9) for a structure with $N$ degrees of freedom can be written as

$$
\begin{array}{r}
J=\lim _{\tau \rightarrow \infty} \frac{1}{\tau} E\left[\int _ { 0 } ^ { \tau } \left(q_{\text {accels }}\left(\sum_{i=1}^{N} \ddot{x}_{i}^{2}+\ddot{x}_{b}^{2}\right)\right.\right. \\
\left.+q_{\text {drift }} x_{b}^{2}+r f_{c}^{2}\right) d t .
\end{array}
$$

The optimal control force is given as follows:

$$
\begin{aligned}
f_{c} & =-k_{c} \bar{z}, \\
\bar{z} & =A \bar{z}+B f+L(y-C \bar{z}-D f),
\end{aligned}
$$


where $k_{c}$ is the gain matrix for the linear quadratic regulator (LQR) and $L$ is the gain matrix for the state estimator which is determined as

$$
\begin{aligned}
& k_{c}=\frac{B^{\prime} P}{r}, \\
& L=(C S)^{\prime},
\end{aligned}
$$

where $P$ and $S$ are the solution of the algebraic Riccati equation given by

$$
\begin{array}{r}
P A+A^{\prime} P-\frac{P B^{\prime} B P}{r}+C^{\prime} Q C=0, \\
S A^{\prime}+A S-S C^{\prime} C S+\gamma E E^{\prime}=0 .
\end{array}
$$

Because MR damper force cannot be changed to the optimal control force directly, the second algorithm is employed to apply MR damper voltage by comparing the MR damper force and the optimal control force. The clipped-optimal control has been used to apply MR damper voltage that is determined as [26]

$$
V=V_{\max } H\left\{\left(f_{c}-f\right) f\right\},
$$

where $V_{\max }$ is the maximum voltage that can be applied to the MR damper, and $H\{$.$\} is the Heaviside step function.$ When the force produced by the MR damper is smaller than the optimal control force and two forces have the same sign, the voltage applied to the MR damper is increased to the maximum level. Otherwise, the voltage applied is set to zero.

\section{Numerical Example}

For numerical analysis, a scaled model of a three-story shear building frame has been considered in fixed-base and baseisolated forms. In the isolated system, an MR damper has been installed between the ground and the base isolation system. The configuration of the considered dynamic model has been shown in Figure 2.

The structural properties of both the fixed-base and the isolated structures are the same taken as $m_{1}=m_{2}=$ $m_{3}=98.3 \mathrm{~kg}, k_{1}=516$ and $k_{2}=k_{3}=684 \mathrm{kN} / \mathrm{m}$, and $c_{1}=125$ and $c_{2}=c_{3}=50 \mathrm{~N} \cdot \mathrm{s} / \mathrm{m}$ [26]. For the isolated system, one degree of freedom is added to the dynamic model of the structure. The properties of this degree of freedom depend on the characteristics of the base isolation system. The base mass $m_{0}$ is chosen equal to the floor mass, and the base damping $c_{0}$ is chosen such that the damping ratio of the isolated mode equals to $2 \%$ of the critical damping [1]. Since the base isolation system is in combination with the MR damper, utilization of high damping base isolation is not needed. The base stiffness $k_{0}$ is also selected such that the natural period of the isolated structure is equal to triple the natural period of the fixed-base structure [30]. So the properties of the base isolation system are $m_{0}=98.3 \mathrm{~kg}, \quad c_{0}=180 \mathrm{~N} \cdot \mathrm{s} / \mathrm{m}$, and $k_{0}=56 \mathrm{kN} / \mathrm{m}$. For numerical simulations, a program has been developed using the MATLAB software. For the isolated shear building considered in the numerical example, the matrices of system in (1) can be written as

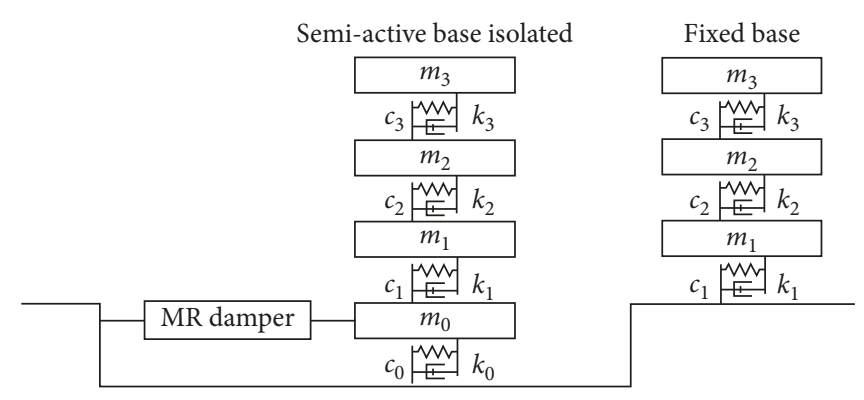

Figure 2: Model of the structure and control system.

TABle 1: Dynamical parameters of the MR damper [26].

\begin{tabular}{lccc}
\hline Parameter & Value & Parameter & Value \\
\hline$c_{0 a}$ & $21 \mathrm{~N} \cdot \mathrm{sec} / \mathrm{cm}$ & $a_{a}$ & $140 \mathrm{~N} / \mathrm{cm}$ \\
$C_{0 b}$ & $3.5 \mathrm{~N} \cdot \mathrm{sec} / \mathrm{cm} \cdot \mathrm{V}$ & $a_{b}$ & $695 \mathrm{~N} / \mathrm{cm} \cdot \mathrm{V}$ \\
$K_{0}$ & $46.9 \mathrm{~N} / \mathrm{cm}$ & $\gamma$ & $363 \mathrm{~cm}$ \\
$C_{1 a}$ & $283 \mathrm{~N} \cdot \mathrm{sec} / \mathrm{cm}$ & $\beta$ & $363 \mathrm{~cm}^{-2}$ \\
$C_{1 b}$ & $2.95 \mathrm{~N} \cdot \mathrm{sec} / \mathrm{cm} \cdot \mathrm{V}$ & $A$ & 301 \\
$K_{1}$ & $5 \mathrm{~N} / \mathrm{cm}$ & $n$ & 2 \\
$X_{0}$ & $14.3 \mathrm{~cm}$ & $\eta$ & $190 \mathrm{sec}^{-1}$ \\
\hline
\end{tabular}

$$
\begin{aligned}
M_{s} & =\left[\begin{array}{cccc}
m_{0} & 0 & 0 & 0 \\
0 & m_{1} & 0 & 0 \\
0 & 0 & m_{2} & 0 \\
0 & 0 & 0 & m_{3}
\end{array}\right], \\
C_{s} & =\left[\begin{array}{cccc}
c_{0}+c_{1} & -c_{1} & 0 & 0 \\
-c_{1} & c_{1}+c_{2} & -c_{2} & 0 \\
0 & -c_{2} & c_{2}+c_{3} & -c_{3} \\
0 & 0 & -c_{3} & c_{3}
\end{array}\right], \\
K_{s} & =\left[\begin{array}{cccc}
k_{0}+k_{1} & -k_{1} & 0 & 0 \\
-k_{1} & k_{1}+k_{2} & -k_{2} & 0 \\
0 & -k_{2} & k_{2}+k_{3} & -k_{3} \\
0 & 0 & -k_{3} & k_{3}
\end{array}\right] .
\end{aligned}
$$

The dynamical parameters of the MR damper used in this research are given in Table 1 [26]. The maximum voltage and the capacity of the MR damper have been $2.25 \mathrm{~V}$ and $3000 \mathrm{~N}$, respectively. The design earthquake records are selected randomly while according to regulations of seismic design codes, the earthquake records should be selected based on the seismic conditions of a specific site. Hence, the obtained results from the randomly selected earthquake records are validated under the filtered white noise excitations. By this validation, it can be concluded that the results will be valid for a wide range of earthquakes as well as sits. Also, the design earthquake records should be scaled based on the regulations of seismic design codes while because the considered structure in this paper is a scaled model, the earthquake records cannot be scaled based on the scaling method described in seismic design codes. Therefore, the design earthquake records are employed in the unscaled form. 
TABle 2: Peak response of structures under different earthquakes.

\begin{tabular}{|c|c|c|c|c|c|c|c|c|c|c|c|}
\hline \multirow{2}{*}{ Earthquake } & \multicolumn{4}{|c|}{ Peak acceleration $\left(\mathrm{cm} / \mathrm{s}^{2}\right)$} & \multicolumn{4}{|c|}{ Peak interstory drift $(\mathrm{cm})$} & \multicolumn{3}{|c|}{ Peak base drift $(\mathrm{cm})$} \\
\hline & F-B & S-B-I & P-Off & P-On & F-B & S-B-I & P-Off & $\mathrm{P}-\mathrm{On}$ & S-B-I & P-Off & $\mathrm{P}-\mathrm{On}$ \\
\hline El Centro $(\mathrm{PGA}=0.348 \mathrm{~g}, 1940)$ & 1413 & 217 & 206 & 478 & 0.54 & 0.10 & 0.06 & 0.15 & 1.27 & 0.44 & 0.19 \\
\hline Loma Prieta $(\mathrm{PGA}=0.278 \mathrm{~g}, 1989)$ & 618 & 133 & 211 & 500 & 0.23 & 0.06 & 0.06 & 0.20 & 0.64 & 0.34 & 0.20 \\
\hline Northridge $(\mathrm{PGA}=0.535 \mathrm{~g}, 1994)$ & 678 & 176 & 186 & 237 & 0.30 & 0.09 & 0.04 & 0.07 & 1.09 & 0.29 & 0.18 \\
\hline Petrolia $(\mathrm{PGA}=0.163 \mathrm{~g}, 1992)$ & 324 & 146 & 136 & 164 & 0.13 & 0.07 & 0.04 & 0.05 & 0.90 & 0.26 & 0.15 \\
\hline Parkfield California $(\mathrm{PGA}=0.35 \mathrm{~g}, 1966)$ & 564 & 90 & 323 & 370 & 0.15 & 0.03 & 0.05 & 0.07 & 0.26 & 0.186 & 0.15 \\
\hline Taft $($ PGA $=0.18 \mathrm{~g}, 1952)$ & 529 & 77 & 179 & 279 & 0.21 & 0.03 & 0.04 & 0.07 & 0.37 & 0.25 & 0.17 \\
\hline Average & 688 & 140 & 207 & 338 & 0.26 & 0.06 & 0.05 & 0.10 & 0.76 & 0.29 & 0.17 \\
\hline
\end{tabular}

Numerical analysis conducted in this research can be classified into four cases as follows:

Case (a): base isolation system and supplemental passive MR damper

Case (b): designing semiactive hybrid base isolation system under multiple earthquakes

Case (c): validating the proposed design procedure under filtered white noise excitations

Case (d): assessing the performance of the designed control system under testing earthquakes

5.1. Case (a): Hybrid Base Isolation System and Passive MR Damper. In this case, the performance of hybrid control system is evaluated when the MR damper voltage has been constant and control system acts in the passive form. The maximum responses of structure under different scaled earthquakes have been reported in Table 2 for constant voltages of 0 (P-Off) and $2.25 \mathrm{~V}$ (P-On). Since the considered structure is a scaled model, the earthquake records have been reproduced at five times the recorded rate. The maximum response of the fixed-base (F-B) structure and the controlled structure by using the single base isolation (S-B-I) system has been presented in Table 2.

As shown in Table 2, adding the single base isolation system to the structure decreases the maximum response of fixed-base structure which under multiple excitations the maximum interstory drift and acceleration have been averagely reduced by $77 \%$ and $80 \%$, respectively, while the base drift has been high. For mitigating the peak base drift, the supplemental passive MR damper is employed in combination with base isolation control system. From the results, it is clear that using the passive MR damper has mitigated the maximum base drift of base-isolated structure significantly. About $62 \%$ and $78 \%$ reduction in the average of the maximum base drifts under different excitations has been achieved for the passive-off and passive-on forms, respectively, while the average of the maximum accelerations of isolated structure has been increased about $48 \%$ and $141 \%$ for the passive-off and passive-on forms, respectively.

5.2. Case (b): Designing Semiactive Hybrid Base Isolation System. In this case, the structure subjected to different scaled earthquakes and the semiactive base isolation system has been designed to be effective under multiple excitations. For weighting
TABLE 3: Various sets of $Q$ and corner force weighting parameter.

\begin{tabular}{lcccccc}
\hline Various sets & $A-1$ & $A-2$ & $A-3$ & $A-4$ & $A-5$ & $A-6$ \\
\hline$q_{\text {accels }}$ & 1 & 1 & 1 & 1 & 1 & 1 \\
$q_{\text {drifts }}$ & 1 & $10^{2}$ & $10^{4}$ & $10^{6}$ & $10^{8}$ & $10^{10}$ \\
$r_{1}$ & $10^{-8.6}$ & $10^{-8.6}$ & $10^{-8.6}$ & $10^{-8.3}$ & $10^{-3.7}$ & $10^{-1.5}$ \\
$r_{2}$ & $10^{-3}$ & $10^{-3}$ & $10^{-3}$ & $10^{-2.7}$ & $10^{-0.9}$ & $10^{-0.5}$ \\
$r_{l-a}$ & $10^{-5.8}$ & $10^{-5.8}$ & $10^{-5.8}$ & $10^{-5.5}$ & $10^{-2.3}$ & $10^{-1}$ \\
\hline
\end{tabular}

matrix, $Q$ defined in (9), different combinations of $q_{\text {accels }}$ and $q_{\text {drifts }}$ can be considered. In this paper to evaluate the effect of Q's elements on performance of hybrid control system, six different sets of $q_{\text {accels }}$ and $q_{\text {drifts }}$ have been defined as reported in Table 3 , which cover a wide range of $q_{\text {drifts }} / q_{\text {accels }}$ ratio. In set $(A-1)$, the acceleration and drift are weighted equally in the performance index function, while in set $(A-6)$, drift is weighted much more than acceleration. For each set, the force weighting parameter, $r$, in (9) is determined to minimize the peak superstructure acceleration and base drift, separately or simultaneously.

The proposed method includes two steps: first, the structure subjected to each earthquake separately, and by using different sets of $q_{\text {accels }}$ and $q_{\text {drifts }}$ defined in Table 3 , the peak acceleration of superstructure and base drift of isolated structure are determined through a sensitivity analysis for different values of weighting parameter, $r$. As instance for sets $(A-1)$ and $(A-6)$, the peak response under different earthquakes has been shown in Figures 3 and 4. For other sets of $Q$, similar trends for response variation versus weighting parameter have been obtained as well, which because of space limitation has not been reported here. Then, by using the results obtained in first step for each ground motion, the average of maximum responses are calculated under all earthquakes, for different values of weighting parameter, $r$, and various sets of $Q$. In Figure 5 the result of second step has been presented.

According to the results, it is clear that for the considered structure, the changing pattern of the peak base drift and superstructure acceleration with $r$ is almost similar under different earthquakes. Moreover, for a specific structure, according to the results to have effective performance under multiple earthquakes, an appropriate range can be proposed to select, $r$, for each design objective. For example, as shown in Figure 3(a) for set $(A-1)$, the ranges (a), (b), and (c) are appropriate to minimize the peak base drift, base drift-acceleration, and acceleration, respectively. These ranges are broken by the corner parameters $r_{1}$ and $r_{2}$ which are shown in Table 3 for each set of $Q$. 


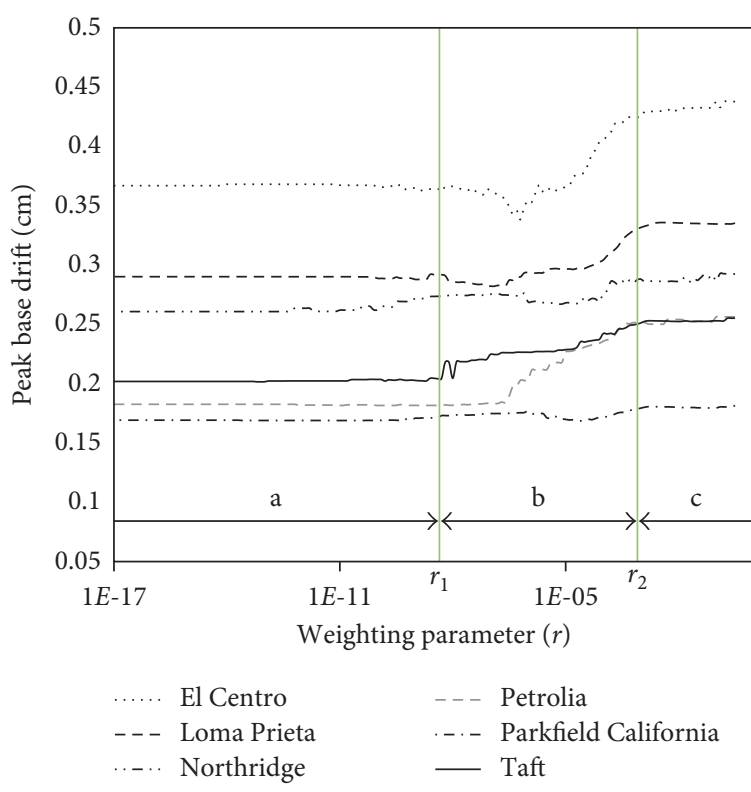

(a)

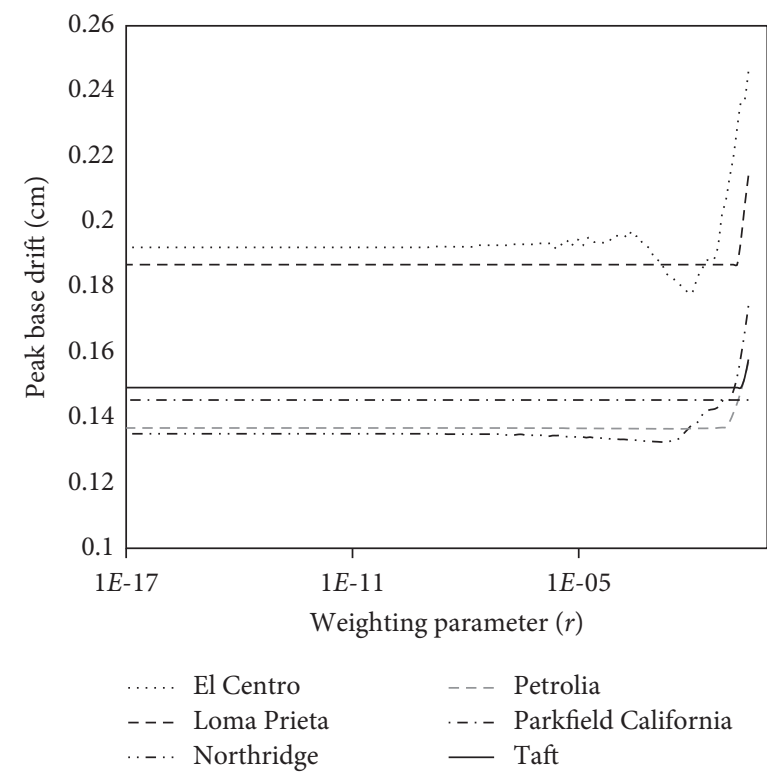

(b)

Figure 3: The peak base drift for sets $(A-1)$ and (A-6). (a) A-1. (b) A-6.

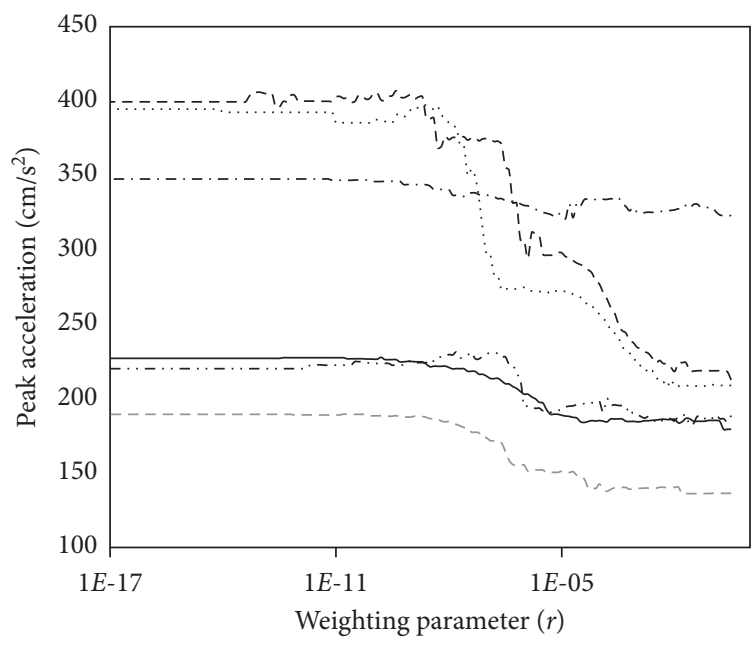

(a)

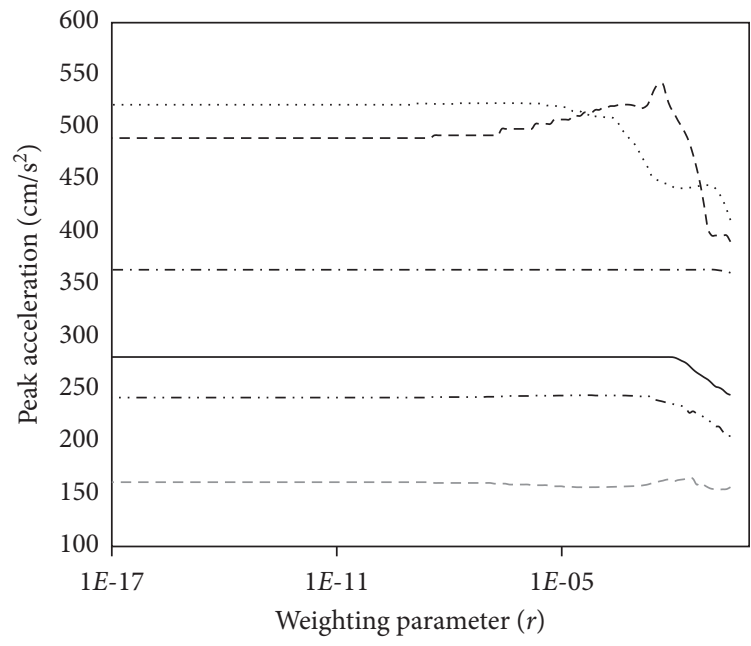

(b)

Figure 4: The peak acceleration for sets $(A-1)$ and (A-6). (a) A-1. (b) A-6.

According to the results, to have more reduction in the averages of maximum base drift and acceleration under multiple earthquakes, it is recommended to select the force weighting parameter, $r$, from ranges (a) and (c), respectively. For example, in this case study, $r=10^{-14}$ and $10^{-0.5}$ are selected from ranges (a) and (c) for minimizing the maximum base drift and acceleration of isolated structure, respectively. According to Figure 5, these values of $r$ are the appropriate selections for all considered sets of $Q$ to minimize the maximum base drift and acceleration. If it is desired to control the acceleration and base drift of the isolated structure simultaneously, depending on the relative importance between the acceleration and base drift, appropriate value for $r$ can be selected from range (b). For each set of $Q$, to control base drift and acceleration simultaneously, in this research, the logarithmic average, $r_{l-a}$ of corner parameters $r_{1}$ and $r_{2}$ has been selected and presented in Table 3. From the results presented in Figure 5, it has been found that under all excitations the minimum values for the peak base drift and superstructure acceleration of the isolated structure has been achieved by using the sets $(A-6)$ and $(A-1)$, respectively. The average of the peak base drift of the isolated structure and the maximum acceleration of the fixed-base structure under design records have been reduced about $79 \%$ and $70 \%$ for sets $(A-6)$ and $(A-1)$, respectively.

The results obtained by using the proposed values for $r$ under multiple records, which has led to $r=10^{-14}, r=r_{l-a}$ (Table 3), and $r=10^{-0.5}$ for the case study of the current research regarding different design objectives, have been 


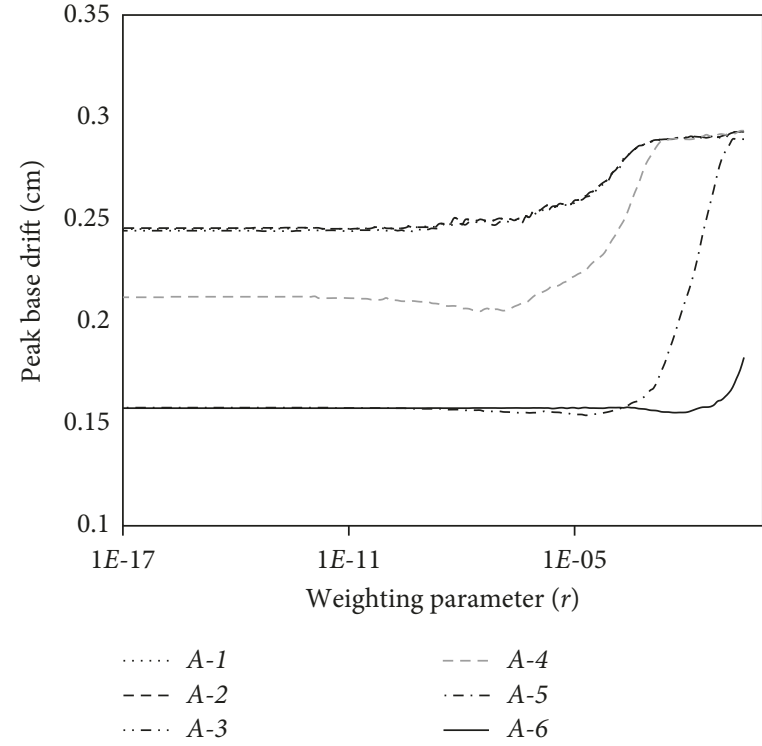

(a)

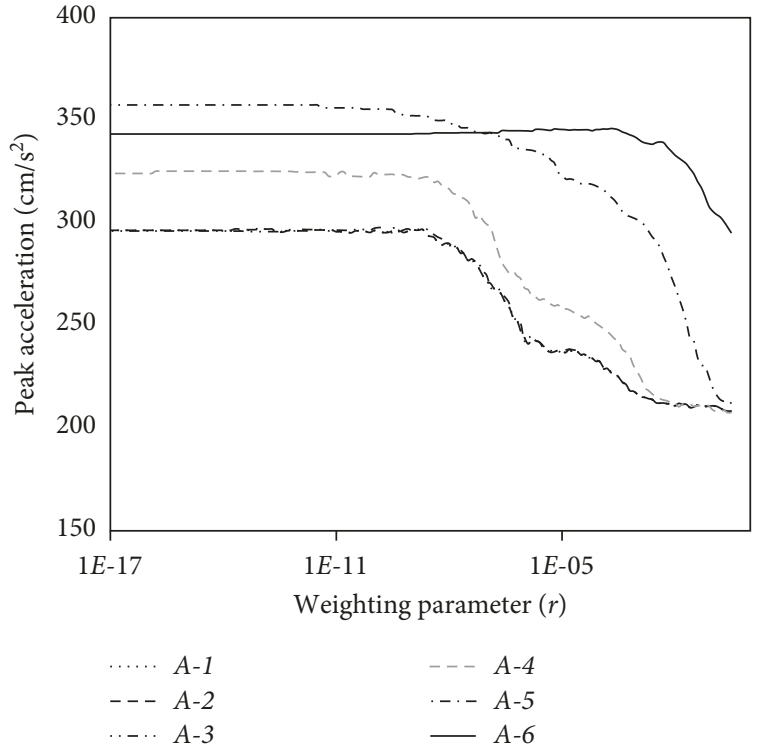

(b)

Figure 5: Average of the peak base drift and acceleration for various sets of Q. (a) Peak base drift. (b) Peak acceleration.

TABle 4: Peak response of structures under different earthquakes for set $(A-1)$.

\begin{tabular}{lcccccccccccc}
\hline \multirow{2}{*}{ Earthquake } & \multicolumn{3}{c}{ Peak acceleration $\left(\mathrm{cm} / \mathrm{s}^{2}\right)$} & \multicolumn{3}{c}{ Peak interstory drift $(\mathrm{cm})$} & \multicolumn{3}{c}{ Peak base drift $(\mathrm{cm})$} \\
& Optimal case & $r=10^{-0.5}$ & $r_{l-a}$ & $r=10^{-14}$ & $r=10^{-0.5}$ & $r_{l-a}$ & $r=10^{-14}$ & $r=10^{-0.5}$ & $r_{l-a}$ & $r=10^{-14}$ & Optimal case \\
\hline El Centro & 208 & 209 & 272 & 392 & 0.061 & 0.067 & 0.108 & 0.438 & 0.361 & 0.368 & 0.338 \\
Loma Prieta & 213 & 213 & 312 & 400 & 0.062 & 0.067 & 0.103 & 0.335 & 0.293 & 0.290 & 0.282 \\
Northridge & 182 & 189 & 195 & 220 & 0.045 & 0.045 & 0.054 & 0.292 & 0.269 & 0.261 & 0.261 \\
Petrolia & 136 & 136 & 152 & 189 & 0.037 & 0.037 & 0.039 & 0.256 & 0.211 & 0.183 & 0.182 \\
Parkfield California & 321 & 323 & 328 & 348 & 0.047 & 0.053 & 0.055 & 0.182 & 0.175 & 0.169 & 0.169 \\
Taft & 179 & 179 & 201 & 227 & 0.040 & 0.051 & 0.057 & 0.255 & 0.227 & 0.202 & 0.202 \\
\hline
\end{tabular}

TABLE 5: Peak response of structures under different earthquakes for set $(A-6)$.

\begin{tabular}{lcccccccccccc}
\hline \multirow{2}{*}{ Earthquake } & \multicolumn{3}{c}{ Peak acceleration $\left(\mathrm{cm} / \mathrm{s}^{2}\right)$} & \multicolumn{3}{c}{ Peak interstory drift $(\mathrm{cm})$} & \multicolumn{4}{c}{ Peak base drift $(\mathrm{cm})$} \\
& Optimal case & $r=10^{-0.5}$ & $r_{l-a}$ & $r=10^{-14}$ & $r=10^{-0.5}$ & $r_{l-a}$ & $r=10^{-14}$ & $r=10^{-0.5}$ & $r_{l-a}$ & $r=10^{-14}$ & Optimal case \\
\hline El Centro & 412 & 412 & 444 & 522 & 0.094 & 0.118 & 0.134 & 0.246 & 0.214 & 0.192 & 0.178 \\
Loma Prieta & 391 & 391 & 397 & 490 & 0.130 & 0.151 & 0.150 & 0.214 & 0.187 & 0.187 & 0.187 \\
Northridge & 205 & 205 & 218 & 242 & 0.060 & 0.067 & 0.070 & 0.174 & 0.146 & 0.135 & 0.132 \\
Petrolia & 154 & 157 & 155 & 161 & 0.043 & 0.047 & 0.050 & 0.157 & 0.139 & 0.137 & 0.137 \\
Parkfield California & 361 & 361 & 364 & 364 & 0.058 & 0.059 & 0.059 & 0.145 & 0.145 & 0.145 & 0.145 \\
Taft & 245 & 245 & 256 & 281 & 0.060 & 0.060 & 0.060 & 0.158 & 0.149 & 0.149 & 0.149 \\
\hline
\end{tabular}

TABLE 6: Average of the peak responses for various sets of $Q$.

\begin{tabular}{lccccccccccc}
\hline \multirow{2}{*}{ Various sets } & \multicolumn{3}{c}{ Peak acceleration $\left(\mathrm{cm} / \mathrm{s}^{2}\right)$} & \multicolumn{3}{c}{ Peak interstory drift $(\mathrm{cm})$} & \multicolumn{4}{c}{ Peak base drift $(\mathrm{cm})$} \\
& Optimal case & $r=10^{-0.5}$ & $r_{l-a}$ & $r=10^{-14}$ & $r=10^{-0.5}$ & $r_{l-a}$ & $r=10^{-14}$ & $r=10^{-0.5}$ & $r_{l-a}$ & $r=10^{-14}$ & Optimal case \\
\hline$A-1$ & 207 & 208 & 243 & 296 & 0.049 & 0.053 & 0.069 & 0.293 & 0.256 & 0.245 \\
$A-2$ & 207 & 208 & 243 & 296 & 0.049 & 0.053 & 0.069 & 0.293 & 0.256 & 0.245 \\
$A-3$ & 207 & 208 & 243 & 296 & 0.049 & 0.053 & 0.069 & 0.293 & 0.255 & 0.244 \\
$A-4$ & 207 & 208 & 263 & 325 & 0.049 & 0.060 & 0.076 & 0.293 & 0.217 & 0.212 \\
$A-5$ & 210 & 212 & 283 & 357 & 0.049 & 0.069 & 0.093 & 0.289 & 0.196 & 0.158 \\
$A-6$ & 295 & 295 & 306 & 343 & 0.074 & 0.084 & 0.087 & 0.182 & 0.163 & 0.158 & 0.153 \\
\hline
\end{tabular}


reported in Tables 4 and 5 for sets $(A-1)$ and $(A-6)$ as the best sets for controlling the maximum superstructure acceleration and base drift, for each excitation while the average values under all records are given in Table 6 for all considered sets of $Q$. The results show that the proposed method for designing semiactive base isolation system has worked successfully under multiple excitations regarding the design objectives. Also, to evaluate the efficiency of the proposed method, the maximum response under each excitation for the case that the control system has been designed optimally for each earthquake separately has been given in Tables 4 and 5 for sets $(A-1)$ and $(A-6)$, too, while for all sets of $Q$, the average of corresponding values under all design records has been presented in Table 6. The results show that the maximum responses and their averages obtained by using $r=10^{-14}$ and $r=10^{-0.5}$ for mitigating the maximum base drift and acceleration have been very close to the optimal case under each earthquake separately. For example, as shown in Table 6 for set $(A-1)$, when the control system is designed optimally for each earthquake separately, the averages of the peak accelerations and base drifts under design excitations are $207 \mathrm{~cm} / \mathrm{s}^{2}$ and $0.239 \mathrm{~cm}$, while by using the proposed method, the corresponding values have been $208 \mathrm{~cm} / \mathrm{s}^{2}$ and $0.245 \mathrm{~cm}$ which are very close together. Therefore, the performance of control the system designed under multiple records by using the proposed method has been very close to the optimal case under each earthquake. In addition, if only one excitation is used for designing the control system, the control system may not have the most effective performance under multiple earthquakes. As instance, if only the Parkfield California earthquake is considered as the design record, $r$ is determined as $10^{-4.6}$ regarding the objective of minimizing the peak base drift as shown in Figure 3(a). For this $r$, the average of the peak base drifts under the considered earthquake records is equal to $0.268 \mathrm{~cm}$, while by using the proposed design procedure in this paper and considering the multiple earthquakes, the corresponding value has been $0.245 \mathrm{~cm}$. Therefore, the multiple record-based design works better than the control system designed based on only one excitation.

Comparing the semiactive and passive forms of the hybrid control system (Tables 2 and 6) shows that in addition to using semiactive form, using the passive-off and passiveon forms can be recommended, respectively, to minimize the maximum acceleration and the maximum base drift. However, using the semiactive form because of its adaptation capability to different conditions is preferred.

5.3. Case (c): Validating the Proposed Design Procedure under Filtered White Noise Excitations. In Section 5.2, for designing the control system under multiple earthquakes, different earthquake records were selected randomly as the design records while selecting earthquake records based on seismic conditions of a specific site has been recommended by the seismic codes. In this section, it is shown that the results obtained in Section 5.2 are independent of the selected earthquake record. To this end, the seismic load is simulated by passing two different Gaussian white noises $(\mathrm{WN})$ processes through the Kanai-Tajimi filter [31,32] with the power spectral density function given by
TABLE 7: Characteristics of the Kanai-Tajimi excitations.

\begin{tabular}{lccc}
\hline Kanai-Tajimi excitation & PGA $(\mathrm{g})$ & $\xi_{g}$ & $\omega_{g}(\mathrm{rad} / \mathrm{s})$ \\
\hline WN I & 0.475 & 0.3 & 37.3 \\
WN II & 0.432 & 0.4 & 60 \\
\hline
\end{tabular}

$$
\begin{aligned}
s(\omega) & =S_{o}\left[\frac{\omega_{g}^{4}+4 \omega_{g}^{2} \xi_{g}^{2} \omega^{2}}{\left(\omega^{2}-\omega_{g}^{2}\right)^{2}+4 \omega_{g}^{2} \xi_{g}^{2} \omega^{2}}\right], \\
S_{o} & =\frac{0.03 \xi_{g}}{\pi \omega_{g}\left(4 \xi_{g}^{2}+1\right)},
\end{aligned}
$$

where $S_{o}$ is the constant spectral density and $\xi_{g}$ and $\omega_{g}$ are the damping and frequency of the ground, respectively. The characteristics of the Kanai-Tajimi excitations used for the numerical simulation are presented in Table 7. The peak base drift and acceleration of structure subjected to the Kanai-Tajimi excitations are reported in Figures 6 and 7 for sets $(A-1)$ and $(A$ 6 ) and different values of $r$. From the results, it is clear that under the Kanai-Tajimi excitations, the changing pattern of the peak base drift with $r$ is almost similar to the changing pattern shown in Section 5.2 for the selected earthquake records. Therefore, it can be concluded that the proposed design method and dividing $r$ into three ranges regarding the design objectives are independent of the selected earthquake record, and if the design records are selected based on seismic conditions of a specific site, the results are consistent with that of Section 5.2.

\subsection{Case (d): Assessing the Performance of Designed Control} System under Testing Earthquakes. To evaluate the performance of control systems designed in Section 5.3, under other earthquakes that are different in the frequency content with the design records, the designed semiactive base isolation systems have been subjected to different scaled ground motions. The maximum response of uncontrolled and controlled structures under testing records has been reported in Table 8 for different types of passive control systems. Also, for the semiactive form, the average of the peak acceleration and base drift under testing earthquakes has been presented in Table 9 for $r=10^{-14}, r=r_{l-a}$, and $r=10^{-0.5}$ obtained for controlling the maximum base drift, base drift-acceleration, and acceleration under multiple design records. As an instance, the force-displacement curve of MR damper force during Olympia (PGA $=0.28 \mathrm{~g}$, 1949) earthquake has been shown in Figure 8 for the P-Off and semiactive control systems. Based on the results under testing records, it is possible to reduce the average of the maximum base drift of isolated structure up to $72 \%$ by using set $(A-6)$ and $r=10^{-14}$ and mitigate the maximum acceleration of fixed-base structure up to $82 \%$ by using set $(A-1)$ and $r=10^{-0.5}$. Hence, the effectiveness of the semiactive control system in reducing different responses under testing records has been proven as well.

For better comparison, the average of maximum response under testing excitations has been determined for different values of $r$ and shown in Figure 9, while the minimum corresponding values are reported in Table 9 for each set of $Q$. From the results, it is clear that under testing records, 


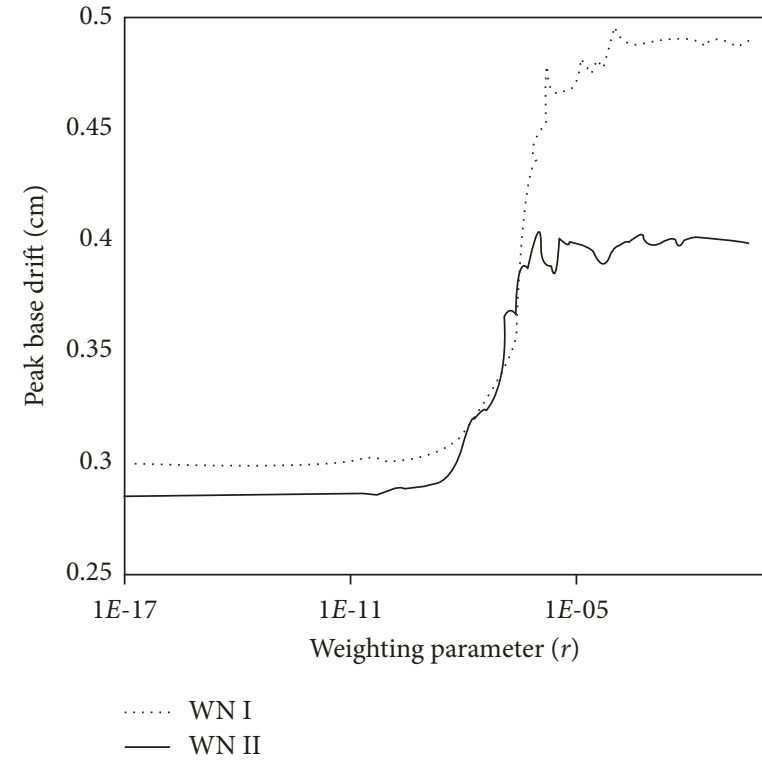

(a)

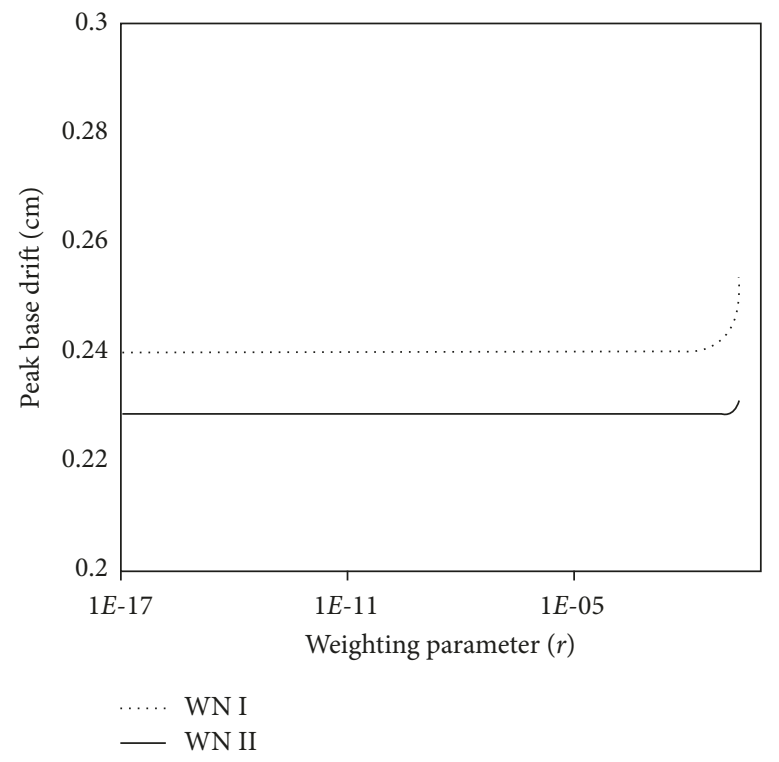

(b)

Figure 6: The peak base drift under the Kanai-Tajimi excitations for sets (A-1) and (A-6). (a) A-1. (b) A-6.

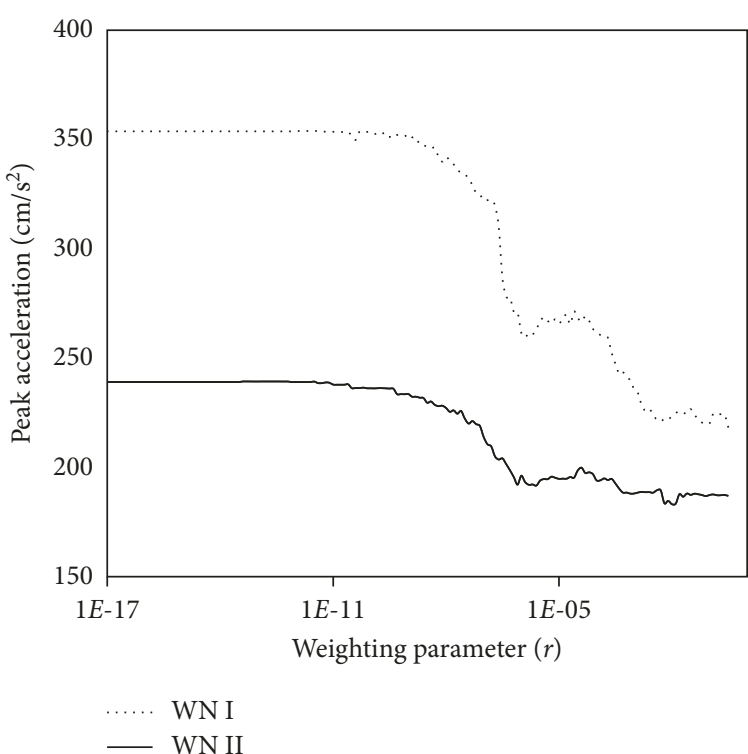

(a)

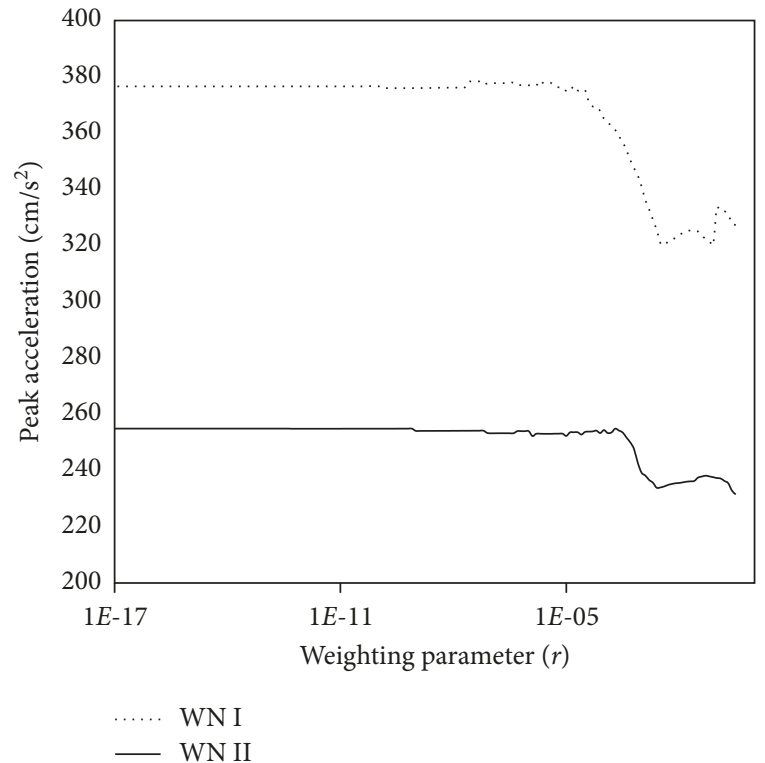

(b)

Figure 7: The peak acceleration under the Kanai-Tajimi excitations for sets (A-1) and (A-6). (a) A-1. (b) A-6.

TABLE 8: Peak response of structures under testing earthquakes.

\begin{tabular}{|c|c|c|c|c|c|c|c|c|c|c|c|}
\hline \multirow{2}{*}{ Earthquake } & \multicolumn{4}{|c|}{ Peak acceleration $\left(\mathrm{cm} / \mathrm{s}^{2}\right)$} & \multicolumn{4}{|c|}{ Peak interstory drift $(\mathrm{cm})$} & \multicolumn{3}{|c|}{ Peak base drift $(\mathrm{cm})$} \\
\hline & F-B & S-B-I & P-Off & P-On & F-B & S-B-I & P-Off & $\mathrm{P}-\mathrm{On}$ & S-B-I & P-Off & $\mathrm{P}-\mathrm{On}$ \\
\hline Olympia (PGA = $0.28 \mathrm{~g}, 1949)$ & 840 & 156 & 177 & 284 & 0.28 & 0.08 & 0.04 & 0.07 & 0.93 & 0.25 & 0.17 \\
\hline San Helena Montana $(\mathrm{PGA}=0.146 \mathrm{~g}, 1935)$ & 306 & 36 & 113 & 170 & 0.13 & 0.02 & 0.03 & 0.07 & 0.21 & 0.18 & 0.12 \\
\hline Northridge $(\mathrm{PGA}=0.344 \mathrm{~g}, 1994)$ & 1728 & 117 & 205 & 514 & 0.68 & 0.05 & 0.06 & 0.22 & 0.52 & 0.45 & 0.20 \\
\hline Taft $($ PGA $=0.156 \mathrm{~g}, 1952)$ & 727 & 97 & 145 & 256 & 0.32 & 0.04 & 0.03 & 0.06 & 0.52 & 0.18 & 0.15 \\
\hline Average & 900 & 102 & 160 & 306 & 0.35 & 0.05 & 0.04 & 0.11 & 0.54 & 0.27 & 0.16 \\
\hline
\end{tabular}


TABle 9: Average of the peak responses for various sets of response weighting parameters under testing earthquakes.

\begin{tabular}{lccccccccccc}
\hline \multirow{2}{*}{ Various sets } & \multicolumn{3}{c}{ Peak Acceleration $\left(\mathrm{cm} / \mathrm{s}^{2}\right)$} & \multicolumn{3}{c}{ Peak interstory drift $(\mathrm{cm})$} & \multicolumn{3}{c}{ Peak base drift $(\mathrm{cm})$} \\
& Optimal case & $r=10^{-0.5}$ & $r_{l-a}$ & $r=10^{-14}$ & $r=10^{-0.5}$ & $r_{l-a}$ & $r=10^{-14}$ & $r=10^{-0.5}$ & $r_{l-a}$ & $r=10^{-14}$ & Optimal case \\
\hline$A-1$ & 156 & 160 & 170 & 206 & 0.041 & 0.044 & 0.049 & 0.265 & 0.250 & 0.236 & 0.235 \\
$A-2$ & 156 & 160 & 170 & 206 & 0.041 & 0.044 & 0.049 & 0.265 & 0.250 & 0.236 & 0.235 \\
$A-3$ & 156 & 160 & 172 & 208 & 0.041 & 0.044 & 0.049 & 0.265 & 0.250 & 0.235 & 0.234 \\
$A-4$ & 158 & 160 & 205 & 245 & 0.041 & 0.051 & 0.062 & 0.265 & 0.213 & 0.201 & 0.198 \\
$A-5$ & 163 & 164 & 223 & 339 & 0.042 & 0.059 & 0.089 & 0.263 & 0.185 & 0.151 & 0.151 \\
$A-6$ & 241 & 241 & 269 & 358 & 0.065 & 0.079 & 0.082 & 0.174 & 0.156 & 0.151 & 0.151 \\
\hline
\end{tabular}

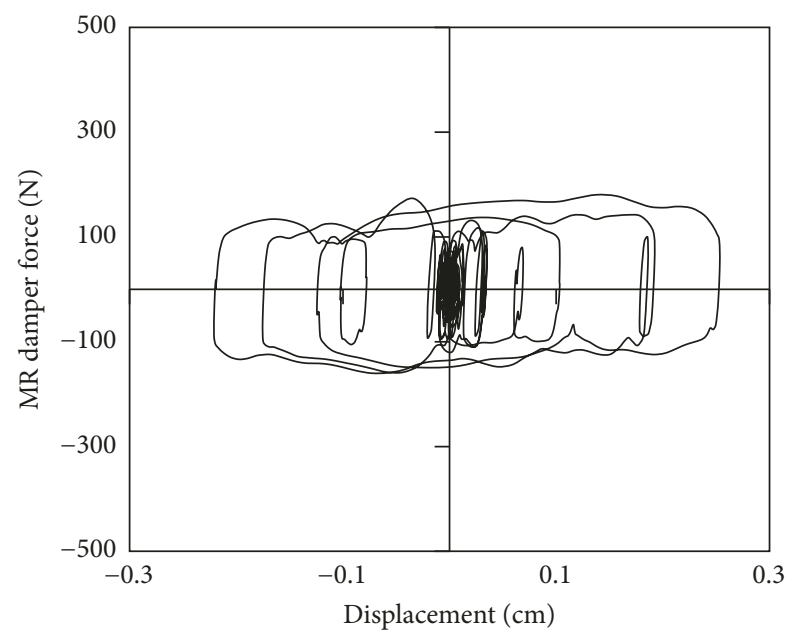

(a)

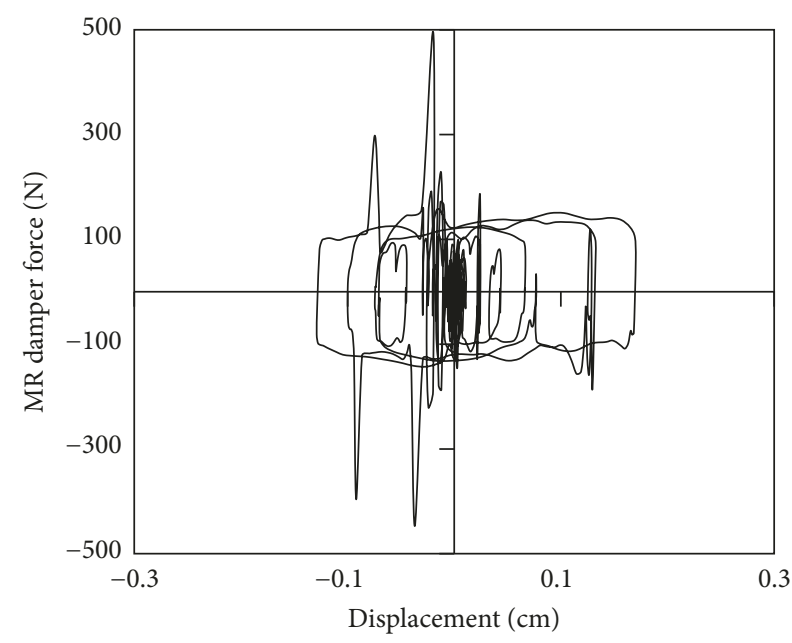

(b)

Figure 8: Force-displacement curve of MR damper force under Olympia earthquake for the P-Off and semiactive controls. (a) P-Off control system. (b) Semiactive control system (set $A-6, r=10^{-14}$ ).
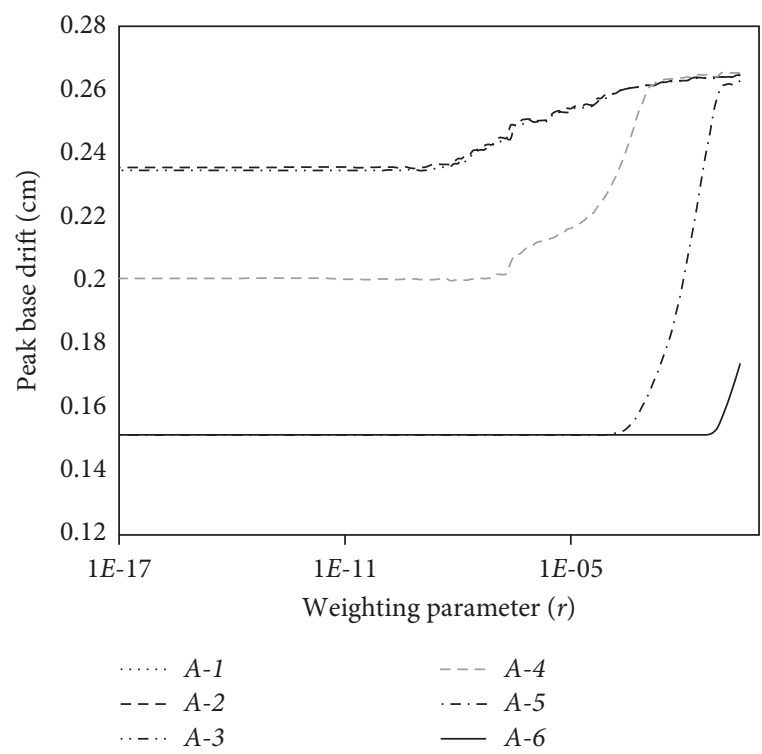

(a)

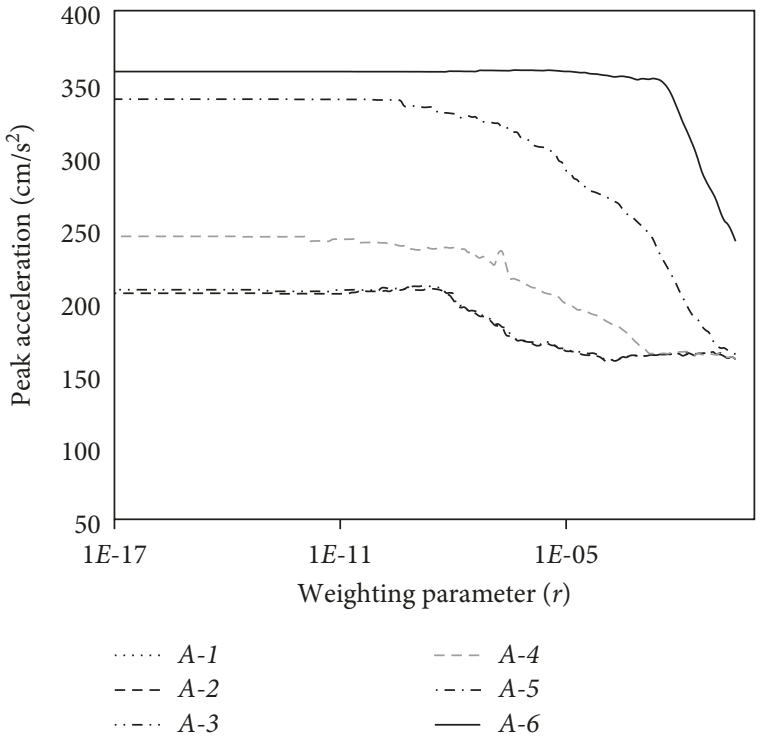

(b)

Figure 9: Average of the peak accelerations and base drifts under testing earthquakes for various sets of response weighting parameters. (a) Peak base drift. (b) Peak acceleration. 
too, the changing pattern of the peak base drift and acceleration with $r$ is the same as design records, and the ranges of (a), (b), and (c) are similar to the results shown in Figure 5 for design records. Hence, from this similarity the effectiveness of the semiactive control system under testing records has been predictable. As shown in Table 9, under testing records, too, the semiactive base isolation system designed by using the method proposed in this research has worked the same as optimal design for each record separately. For example, about $72 \%$ reduction has been achieved in the average of maximum base drift of the isolated structure when using set $(A-6)$ and $r=10^{-14}$, while the corresponding value has been $72 \%$ for the optimal case.

\section{Conclusion}

In this paper, a method has been presented for designing a semiactive control system composed of a low damping base isolation system and a supplemental magnetorheological (MR) damper under multiple earthquake records to mitigate the maximum superstructure acceleration and base drift of the isolated structure. The $\mathrm{H}_{2} /$ linear quadratic Gaussian (LQG) and clipped-optimal control algorithms have been used to determine MR damper force. In the proposed method where the main focus has been designing the semiactive base isolation system to be effective under multiple design records, first the appropriate range for the parameter of control system has been determined for each design objective under each excitation, and then based on mitigating the average of responses under multiple earthquakes, the control system design parameters have been selected. For numerical simulations, a scaled three-story shear building base-isolated frame subjected to different scaled earthquakes and for different sets of response weighting matrix, a semiactive base isolation system has been designed to mitigate the peak base drift and superstructure acceleration separately or simultaneously. In addition, to compare the performance of the semiactive control system with that of the passive hybrid system, the response of the base-isolated structure equipped with passiveoff and passive-on MR dampers has been determined under design earthquakes. According to the results of numerical simulations, the following can be concluded:

(1) Changing pattern of the peak response with the design parameter of control algorithm has been similar under different real earthquakes and filtered white noise excitations. Hence, for a specific structure and for each design objective, a range can be proposed to the weighting parameter that is almost independent from input earthquake.

(2) The semiactive base isolation system designed according to the proposed method under multiple records has been effective in reducing the desired responses which in the current research up to $79 \%$ and $70 \%$ reduction has been achieved in the average of the peak base drift of the isolated structure and the maximum acceleration of the fixed-base structure, respectively.
(3) The performance of semiactive base isolation systems designed under multiple earthquakes to minimize the peak base drift and acceleration have been approximately the same as passive-on and passiveoff forms, respectively.

(4) The most reduction in the peak base drift has been obtained when the assigned weight on drift in the performance index is much more than the acceleration related weighting parameter, and when drift and acceleration are weighted equally, the maximum reduction in the peak acceleration is achieved.

(5) Under testing earthquake records, the average of peak base drift of isolated structure and the maximum acceleration of fixed-base structure have been reduced about $72 \%$ and $82 \%$ by using the proposed design method, while the corresponding values have been $72 \%$ and $83 \%$ when the control system has been designed optimally for each earthquake separately.

Therefore, the proposed method has been an efficient method for designing the semiactive base isolation system under multiple excitations which should be considered in design procedure as per seismic design codes.

\section{Conflicts of Interest}

The authors declare that there are no conflicts of interest regarding the publication of this article.

\section{References}

[1] F. Naeim and J. M. Kelly, Design of Seismic Isolated Structure: From Theory to Practice, Wiley, New York, NY, USA, 1999.

[2] M. C. Constantinou, M. D. Symans, P. Tsopelas, and D. P. Taylor, "Fluid dampers in applications of seismic energy dissipation and seismic isolation," in Proceedings of ATC-17-1 Seminar on Seismic Isolation, Passive Energy Dissipation and Active Control, San Francisco, CA, USA, March 1993.

[3] T. Kobori, M. Takahashi, T. Nasu, N. Niwa, and K. Ogasawara, "Seismic response controlled structure with active variable stiffness system," Earthquake Engineering and Structural Dynamics, vol. 22, no. 11, pp. 925-941, 1993.

[4] J. A. Inaudi and J. M. Kelly, "Hybrid isolation systems for equipment protection," Earthquake Engineering and Structural Dynamics, vol. 22, no. 4, pp. 297-313, 1993.

[5] S. Nagarajaiah, M. A. Riley, and A. Reinhorn, "Control of sliding-isolated bridge with absolute acceleration feedback," Journal of Engineering Mechanics, vol. 119, no. 11, pp. 23172332, 1993.

[6] J. N. Yang, J. C. Wu, A. M. Reinhorn, and M. Riley, "Control of sliding-isolated buildings using sliding-mode control," Journal of Structural Engineering, vol. 122, no. 2, pp. 179-186, 1996.

[7] G. J. Madden, M. D. Symans, and N. Wongprasert, "Experimental verification of seismic response of building frame with adaptive sliding base-isolation system," Journal of Structural Engineering, vol. 128, no. 8, pp. 1037-1045, 2002.

[8] N. Wongprasert and M. D. Symans, "Experimental evaluation of adaptive elastomeric base-isolated structures using variable-orifice fluid dampers," Journal of Structural Engineering, vol. 131, no. 6, pp. 867-877, 2005. 
[9] S. Narasimhan and S. Nagarajaiah, "A STFT semiactive controller for base isolated buildings with variable stiffness isolation systems," Engineering Structures, vol. 27, no. 4, pp. 514-523, 2005.

[10] S. Nagarajaiah and S. Sahasrabudhe, "Seismic response control of smart sliding isolated buildings using variable stiffness systems: an experimental and numerical study," Earthquake Engineering and Structural Dynamics, vol. 35, no. 2, pp. 177-197, 2006.

[11] F. Weber, H. Distl, and C. Braun, "Semi-active base isolation of civil engineering structures based on optimal viscous damping and zero dynamic stiffness," in Proceedings of the IMAC-XXXV Conference and Exposition on Structural Dynamics, pp. 1-9, Garden Grove, CA, USA, February 2017.

[12] Y. Z. Lin and R. Christenson, "Real-time hybrid test validation of a MR damper controlled building with shake table tests," Advances in Structural Engineering, vol. 14, no. 1, pp. 79-92, 2011.

[13] S. D. Bharti, S. M. Dumne, and M. K. Shrimali, "Earthquake response of asymmetric building with MR damper," Earthquake Engineering and Engineering Vibration, vol. 13, no. 2, pp. 305-316, 2014.

[14] B. Erkus and E. A. Johnson, "Dissipativity analysis of the base isolated benchmark structure with magnetorheological fluid dampers," Smart Materials and Structures, vol. 20, no. 10, p. 105001, 2011.

[15] Y. Wang and S. J. Dyke, "Modal-base LQG for smart base isolation system design in seismic response control," Structural Control and Health Monitoring, vol. 20, no. 5, pp. 753-768, 2013.

[16] B. Chen, Y. Z. Sun, Y. L. Li, and S. L. Zhao, "Control of seismic response of a building frame by using hybrid system with magnetorheological dampers and isolators," Advances in Structural Engineering, vol. 17, no. 8, pp. 1199-1215, 2014.

[17] H. S. Kim and J. W. Kang, "Multi-objective fuzzy control of smart base isolated spatial structure," International Journal of Steel Structures, vol. 14, no. 3, pp. 547-556, 2014.

[18] M. Mohebbi and H. Dadkhah, "Multi-objective semi-active base isolation system," International Journal of Optimization in Civil Engineering, vol. 7, no. 3, pp. 319-338, 2017.

[19] J. C. Ramallo, E. A. Johnson, and B. F. Spencer, "Smart base isolation systems," Journal of Engineering Mechanics, vol. 128, no. 10, pp. 1088-1099, 2002.

[20] S. Sahasrabudhe and S. Nagarajaiah, "Experimental study of sliding base-isolation buildings with magnetorheological dampers in near-fault earthquake," Journal of Structural Engineering, vol. 131, no. 7, pp. 1025-1034, 2005.

[21] E. A. Johnson, J. C. Ramallo, B. F. Spencer, and M. K. Sain, "Intelligent base isolation systems," in Proceedings of 2 nd World Conference on Structural Control, pp. 367-376, Kyoto, Japan, June 1998.

[22] H. Yoshioka, J. C. Ramallo, and B. F. Spencer, "Smart base isolation strategies employing magnetorheological dampers," Journal of Engineering Mechanics, vol. 128, no. 5, pp. 540-551, 2002.

[23] M. Mohebbi, H. Dadkhah, and K. Shakeri, "Optimal hybrid base isolation and MR damper," International Journal of Optimization in Civil Engineering, vol. 5, no. 4, pp. 493-509, 2015.

[24] S. F. Ali and A. Ramaswamy, "Hybrid structural control using magnetorheological dampers for base isolated structures," Smart Materials and Structures, vol. 18, no. 5, p. 055011, 2009.

[25] Y. F. Du, X. Zhu, H. Li, and G. H. Wang, "Collapse simulation of plan irregular isolation structures subjected to near-fault seismic motion," Applied Mechanics and Materials, vol. 433435, pp. 2290-2294, 2013.

[26] S. J. Dyke, B. F. Spencer, M. K. Sain, and J. D. Carlson, "Modeling and control of magnetorheological dampers for seismic response reduction," Smart Materials and Structures, vol. 5, no. 5, pp. 565-575, 1996.

[27] B. F. Spencer, S. J. Dyke, M. K. Sain, and J. D. Carlson, "Phenomenological model for magnetorheological dampers," Journal of Engineering Mechanics, vol. 123, no. 3, pp. 230-238, 1997.

[28] L. M. Jansen and S. J. Dyke, "Semi-active control strategies for MR damper: a comparative study," Journal of Engineering Mechanics, vol. 126, no. 8, pp. 795-803, 2000.

[29] M. Mohebbi and A. Joghataie, "Designing optimal tuned mass dampers for nonlinear frames by distributed genetic algorithms," Structural Design of Tall and Special Buildings, vol. 21, no. 1, pp. 57-76, 2012.

[30] R. Villaverde, Fundamental Concepts of Earthquake Engineering, Taylor and Francis Group, New York, NY, USA, 2009.

[31] H. Tajimi, "A statistical method of determining the maximum response of a building structure during an earthquake," in Proceedings of 2 nd World Conference in Earthquake Engineering, pp. 781-797, Tokyo, Japan, July 1960.

[32] K. Kanai, "An empirical formula for the spectrum of strong earthquake motions," in Bulletin Earthquake Research Institute, University of Tokyo, Tokyo, Japan, vol. 39, pp. 85-95, 1961. 


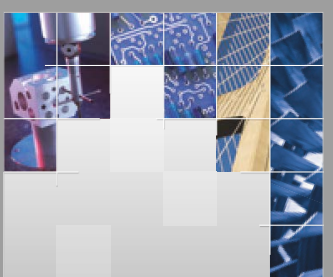

\section{Enfincering}
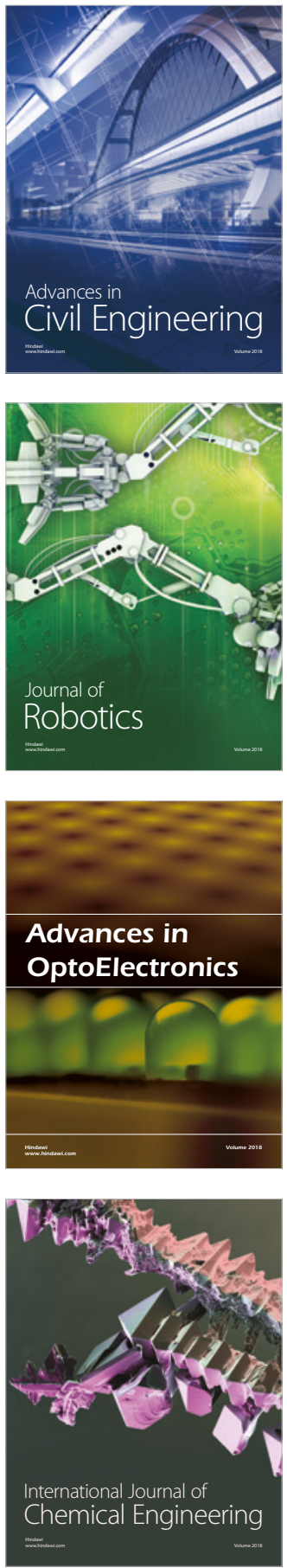

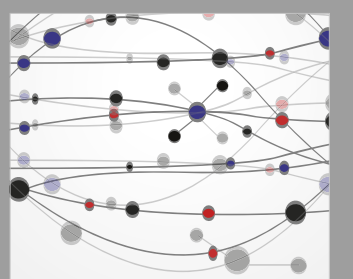

\section{Rotating \\ Machinery}

The Scientific World Journal

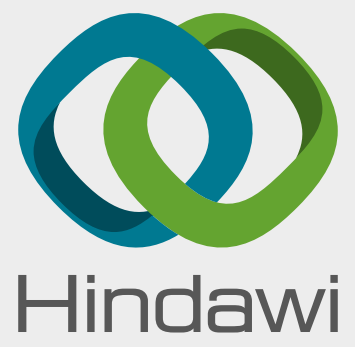

Submit your manuscripts at

www.hindawi.com
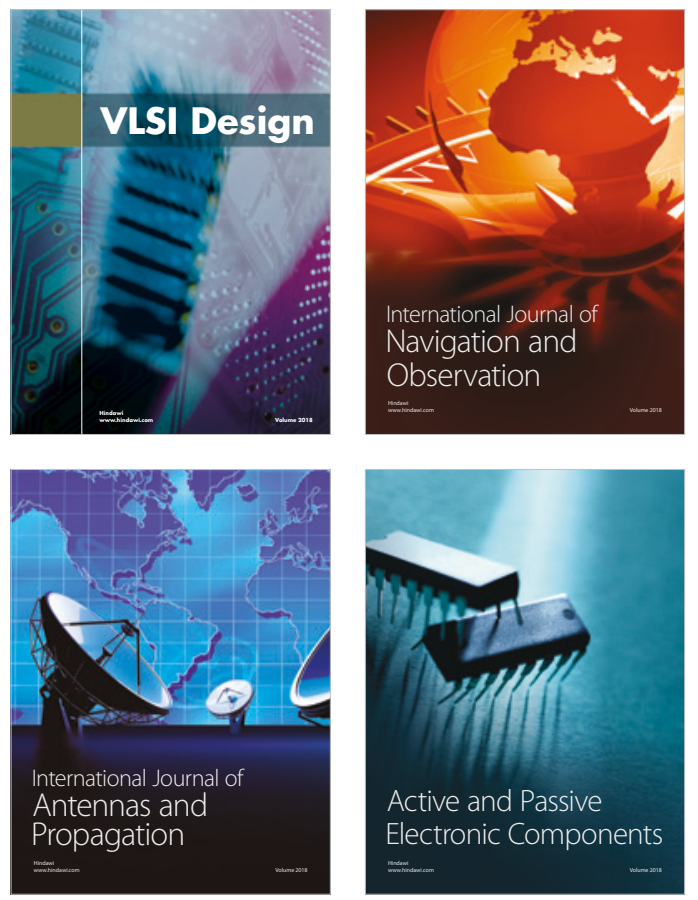
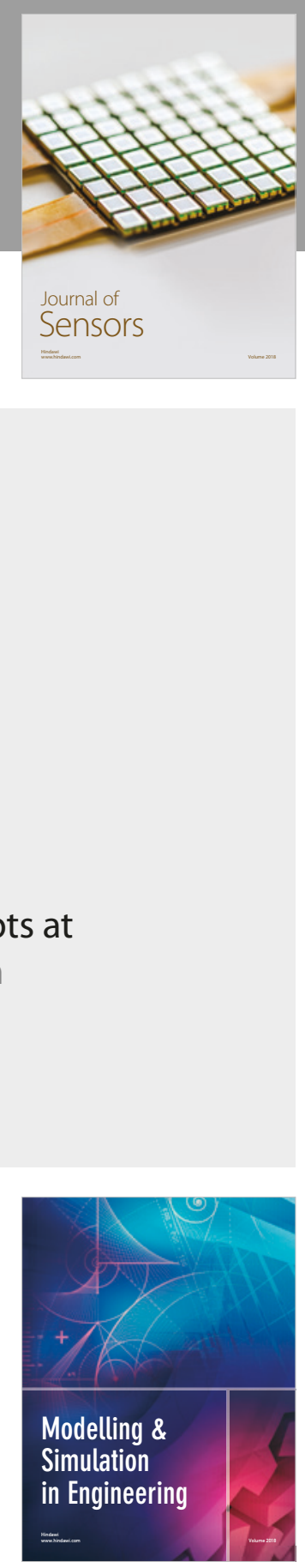

\section{Advances \\ Multimedia}
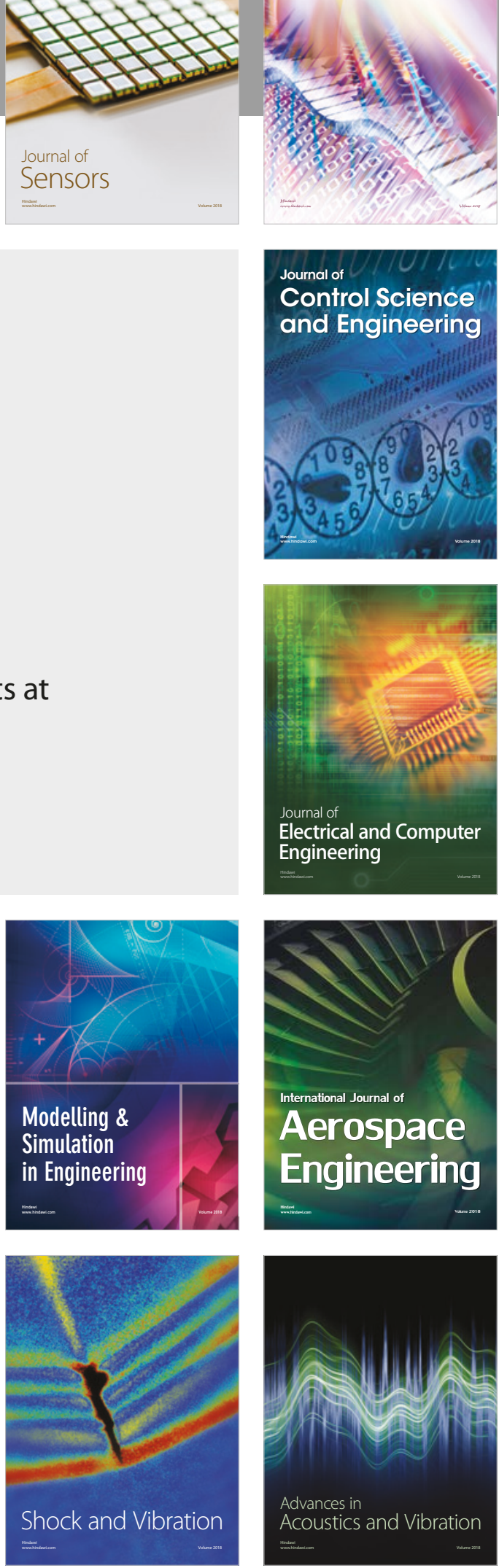